\title{
Analyzing non-sentinel axillary metastases in patients with T3-T4 cNO early breast cancer and tumor-involved sentinel lymph nodes undergoing breast-conserving therapy or mastectomy
}

\author{
Fabian Riedel ${ }^{1}$. Joerg Heil ${ }^{1}$ Manuel Feisst ${ }^{2}$ - Mareike Moderow ${ }^{3}$. Alexandra von Au ${ }^{1}$. Christoph Domschke ${ }^{1}$. \\ Laura Michel $^{1} \cdot$ Benedikt Schaefgen ${ }^{1} \cdot$ Michael Golatta $^{1} \cdot$ André Hennigs $^{1}$
}

Received: 21 March 2020 / Accepted: 10 August 2020 / Published online: 20 August 2020

(c) The Author(s) 2020

\begin{abstract}
Purpose In the ACOSOG Z0011 trial, completing axillary lymph node dissection (cALND) did not benefit patients with T1-T2 cN0 early breast cancer and 1-2 positive sentinel lymph nodes (SLN) undergoing breast-conserving surgery (BCT). This paper reports cALND rates in the clinical routine for patients who had higher (T3-T4) tumor stages and/or underwent mastectomy but otherwise met the ACOSOG Z0011 eligibility criteria. Aim of this study is to determine cALND time trends and non-sentinel axillary metastases (NSAM) rates to estimate occult axillary tumor burden.

Methods Data were included from patients treated in 179 German breast cancer centers between 2008 and 2015. Time-trend rates were analyzed for CALND of patients with T3-T4 tumors separated for BCT and mastectomy and regarding presence of axillary macrometastases or micrometastases.

Results Data were available for 188,909 patients, of whom 19,009 were identified with 1-2 positive SLN. Those 19,009 patients were separated into 4 cohorts: (1) Patients with T1-T2 tumors receiving BCT (ACOSOG Z0011 eligible; $n=13,741$ ), (2) T1-T2 with mastectomy $(n=4093)$, (3) T3-T4 with BCT $(n=269)$, (4) T3-T4 with mastectomy $(n=906)$. Among patients with T3-T4 tumors, cALND rates declined from 2008 to 2015: from 88.2 to $62.6 \%$ for patients receiving mastectomy and from 96.6 to $58.1 \%$ in patients receiving BCT. Overall rates for any NSAM after cALND for cohorts $1-4$ were $33.4 \%$, $42.3 \%, 46.9 \%, 58.8 \%$, respectively.

Conclusions The cALND rates have decreased substantially in routine care in patients with 'extended' ACOSOG Z0011 eligibility criteria. Axillary tumor burden is higher in these patients than in the ACOSOG Z0011 trial.
\end{abstract}

Keywords Breast cancer $\cdot$ Axillary lymph node dissection $\cdot$ Sentinel lymph node dissection $\cdot$ Non-sentinel axillary metastases $\cdot$ ACOSOG Z0011 trial

André Hennigs

andre.hennigs@med.uni-heidelberg.de

1 Department of Gynecology and Obstetrics, Heidelberg University Hospital, Im Neuenheimer Feld 440, 69120 Heidelberg, Germany

2 Institute of Medical Biometry and Informatics, Heidelberg University Hospital, Im Neuenheimer Feld 130.3, 69120 Heidelberg, Germany

3 West German Breast Center GmbH, Bahlenstr. 180, 40589 Düsseldorf, Germany

\section{Introduction}

Surgical management of early breast cancer (EBC) comprises margin-free removal of the tumor from the breast and histopathologic determination of axillary lymph node status. The lymph node status is necessary for estimating individual prognosis regarding cancer recurrence in the treatment decision process for adjuvant therapy, i.e. radiotherapy [1] or chemotherapy [2]. So lymph node sampling has a diagnostic value in this context and can be performed either by the selective removal of sentinel lymph node(s) (SLN) or by a systematic axillary lymph node dissection (ALND). The extent of radical surgery to the axilla, and the accompanying morbidity, has been reduced through implementation of axillary staging via SLN dissection (SLND). SLND 
is the standard procedure for axillary staging in clinically node-negative patients [3]. For patients with affected SLN, a subsequent completing ALND (cALND) had been recommended [4].

The practice-changing results from the American College of Surgeons Oncology Group (ACOSOG) Z0011 trial called into question the practice of cALND [5]. This trial assessed the impact of omitting cALND in clinically node-negative (cN0) EBC patients undergoing breast-conserving therapy (BCT) with tumors size $\leq 5 \mathrm{~cm}$ (i.e. T1-T2) and 1 or 2 positive SLN. SLND alone resulted in equivalent loco-regional control, disease-free survival, and overall survival rates in comparison to cALND at 10-year follow-up [6]. Remarkably, the cALND group contained 97 out of 355 patients (27.3\%) with additional non-sentinel axillary metastasis (NSAM) in lymph nodes removed by cALND. This implied that unremoved tumor-affected axillary lymph nodes seem not to be prognostically relevant for many patients when receiving guideline-adherent adjuvant treatment. Thus, the identification of occult axillary metastases does not appear to result in improved oncological outcome [7].

However, the ACOSOG Z0011 trial has been criticized for its low statistical power because of slow recruitment and premature termination of the study. Furthermore, mainly low-risk patients were included, which may have influenced survival outcomes. So the applicability of the trial results to routine clinical practice has been questioned $[8,9]$. Nevertheless, the idea of omitting cALND in subgroups has been analyzed in further randomized controlled trials (RCTs): first for axillary micrometastases in the IBCSG 23-01 trial [10, 11], but then also in specific radiotherapy settings, such as in the AMAROS trial [12] or the OTOASOR trial [13]. These trials confirmed the results of ACOSOG Z0011, showing no oncological benefit for cALND with even higher rates of NSAM. Comparable NSAM rates were also found in a study on a German cohort that met ACOSOG Z0011 eligibility criteria yet was treated with cALND [14].

The results from the ACOSOG trial have been incorporated into guidelines [15] and the clinical routine [3, 16], but surgeon acceptance still underlies high variability [17]. On the other hand, clinical practice based on the ACOSOG Z0011 results has the advantages of reducing morbidity [18] and healthcare costs [19].

It is the aim to identify further patient populations in which a reduced axillary surgery is possible without comprising oncological outcome. The application of the clinical recommendations based on ACOSOG Z0011 also to patients with higher tumor stages (T3-T4) and to patients undergoing mastectomy are being discussed [20] and to some extent are already being implemented in the clinical routine for SLNpositive patients [21,22].

In this study we evaluated patients with 'extended' ACOSOG Z0011 criteria by analyzing the annual rate of cALND in a large prospectively collected cohort from 179 German breast cancer units (BCU). Furthermore, we compared the rates of NSAM in a cohort of patients who met ACOSOG Z0011 eligibility criteria except for having higher tumor stages and/or mastectomy versus a cohort who did meet all ACOSOG Z0011 eligibility criteria. For the evaluation of NSAM, four cohorts were compared: (1) patients who met all ACOSOG Z0011 eligibility criteria, (2) patients who met all ACSOGO Z0011 eligibility criteria but had mastectomy, (3) patients who met all ACSOGO Z0011 eligibility criteria but had T3-T4 tumors (yet still received BCT), (4) patients who met all ACSOGO Z0011 eligibility criteria but had T3-T4 tumors and mastectomy. Additionally, factors associated with the performance of cALND in T3-T4 cohorts were identified using multivariable logistic regression analyses.

The aim of this study is to present an estimation of occult axillary tumor burden in cohorts who do not met all ACOSOG eligibility criteria to support clinical decision-making.

\section{Methods}

\section{Database}

Data were obtained from a voluntary benchmarking project in Germany. The participating units contributed clinical, surgical, and pathological data from patients with EBC to the West German Breast Center (WBC), Düsseldorf, Germany. All patient treated at one of the participating units are automatically registered in the database. The WBC provides quality control through an annual benchmarking report [23]. The data are also used for the German Cancer Society's periodical re-certification process to be a certified BCU. Collaborating BCUs collected the data prospectively. Thus, this is a post hoc analysis of registry data.

The validity and quality of the data registered in the WBC tumor documentation system are assessed through a detailed benchmarking system. Comparative quality assessment through benchmarking requires accurate recording of treatment data. The credibility of the tumor documentation is examined for validation purposes. Besides the statistical data-check procedures, in-house data monitoring by clinical research associates is performed twice per year in the participating BCUs.

The study was approved by the ethics committee of the University of Heidelberg and was conducted in accordance with the Declaration of Helsinki. The study was deemed to be without risk, including only analysis of anonymized, routinely collected data; consequently, the ethics committee of the University of Heidelberg did not request approval for patient consent for this designated analysis. Informed consent was obtained from all individual participants for the data acquisition of the benchmarking process. 


\section{Eligibility criteria}

For this analysis, anonymized data from all patients with EBC treated between 1 January 2008 and 31 December 2015 were obtained from the WBC database. From this dataset, 4 cohorts of patients were extracted with clinically negative lymph nodes and 1-2 affected SLN: (1) patients with T1-T2 tumors receiving $\mathrm{BCT},(2)$ patients with $\mathrm{T} 1-\mathrm{T} 2$ tumors receiving mastectomy, (3) T3-4 with BCT, (4) T3-4 with mastectomy. The first cohort represents patients who meet all the eligibility criteria of the ACOSOG Z0011 trial. The other three cohorts meet all the eligibility criteria of the ACOSOG Z0011 trial except for having higher tumor stages and/or receiving mastectomy. Adjuvant treatment was performed according to guidelines.

In our study we selected patients for the analysis according to the eligibility criteria of the ACOSOG Z0011 trial by Giuliano et al. shown in Fig. 1. Tumor stages of the patients with the extended ACOSOG Z011 eligible criteria were grouped according to the recent TNM classification including inflammatory breast cancer defined as T4(d). Unlike in the ACOSOG Z0011 trial, all analyses for this study were made using the pathological tumor stage (pT) due to the inconsistent documentation of the clinical tumor (cT) stage in our database. This substitution seems reasonable, given the high concordance between the two types of staging [16]. All participating institutes that provided patient data to the database were labeled before the beginning of the analysis either as university hospitals, academic hospitals (i.e. associated to a university in their function as an academic teaching hospital) or non-academic hospitals. For annual caseload three groups were pre-defined: $100 ; 101-250 ;>250$ cases/ year.

\section{Statistical analysis}

Patient and tumor characteristics were reported as absolute and relative frequencies. Annual percentages of cALND were calculated and presented as a longitudinal time-trend analysis for the period from 2008 to 2015 . This was done for cases with T3-T4 tumors and 1-2 tumor-affected SLN, who were separated for BCT or mastectomy and for presence of sentinel micrometastases or macrometastases. The difference in both variables over the course of time was graphically illustrated and analyzed using logistic regression models with repeated measurements. Multivariable logistic

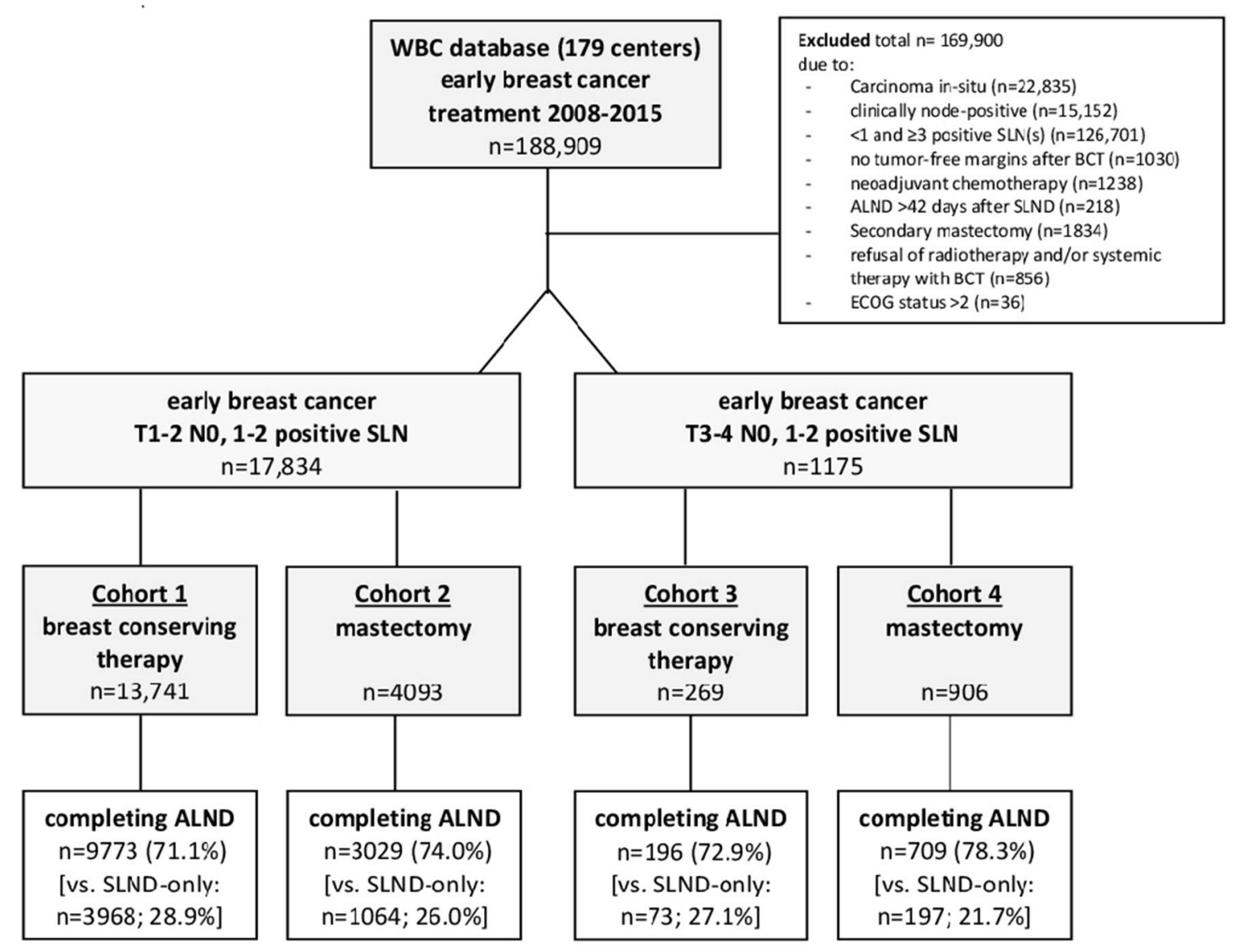

Fig. 1 Consort diagram presenting study cohorts 
regression was used to identify factors associated with performing cALND in patients with T3-T4 cN0 EBC and 1-2 tumor-affected SLN. These regression analyses were restricted to the subset of patients who were treated since the publication of the ACOSOG Z0011 results (in December 2010). Due to the large sample size in the regression analysis $(n=825)$, p-values of $<0.001$ were considered as statistically significant in a descriptive sense. Missing data were not imputed. All statistical analyses were performed with $R$, version 3.5.1.

\section{Results}

\section{Study sample}

The entire study cohort included 188,909 patients with EBC treated between 2008 and 2015 at 179 BCU in Germany. Of these, 169,900 patients were excluded for the reasons shown in Fig. 1, leaving 19,009 patients with clinically node-negative lymph nodes and 1-2 positive SLN (17,843 with T1-T2 and 1175 with T3-T4). These 19,909 patients were then sorted into 4 cohorts: (1) 13,741 patients who met all eligibility criteria for the ACOSOG Z0011 trial,(2) 4093 patients who had mastectomy for T1-T2 tumors, (3) 269 patients who had BCT for T3-T4 tumors, and (4) 906 patients who had mastectomy for T3-T4 tumors. Then cALND was performed (after histological confirmation of metastases in 1-2 SLN) in 9773 patients (71.1\%) in cohort one, 3029 patients (74.0\%) in cohort two, 196 patients $(72.9 \%)$ in cohort three, and 709 patients $(78.3 \%)$ in cohort four. All other patients received SLND only (Fig. 1).

These four cohorts did not differ substantially from each other: most cases were hormone receptor positive, HER2 negative, and had an intermediate tumor grading. Higher median age and more patients with a lower ECOG performance score were seen in cohorts 2-4 in comparison to the ACOSOG Z0011 eligible cohort (cohort 1). Table 1 presents detailed patient and tumor characteristics.

\section{cALND Time-Trend Analyses for T3-T4 CNO and 1-2 positive SLN}

The annual cALND rate declined from $96.6 \%$ (in 2008) to $58.1 \%$ (in 2015) for patients receiving BCT, and from $88.2 \%$ (in 2008) to $62.6 \%$ (in 2015) for patients receiving mastectomy (time trend $p<0.001$; curve separation: $p=0.164$; Fig. 2). The cALND rate declined from 88.9 (in 2008) to $13.3 \%$ (in 2015) for patients with micrometastases (total $54 / 121$ cases), and from 91.0 (in 2008) to $68.2 \%$ (in 2015) for patients with macrometastases (total 851/1054 cases; time trend $p<0.001$, curve separation $p=0.009$; Fig. 3).

\section{Factors associated with performance of CALND}

In multivariable analyses, higher annual hospital case load, younger age, macrometastases, performing a mastectomy and lower number of SLN removed as well as higher number of affected SLN had significant influences on the performance of cALND in patients with T3-T4 cN0 EBC and 1-2 tumor-affected SLN. Immunohistochemical parameters such as positivity for hormone or HER2 receptor and hospital type affiliation were not significant factors (Table 2).

\section{Non-sentinel axillary metastases in the CALND cohorts}

In the cALND of our patients eligible for ACOSOG Z0011 (cohort 1), 3264 out of 9773 cases (33.4\%) were found to have additional NSAM in the axillary lymph node dissection specimens. This rate was higher in the other cohorts: $42.3 \%$ in cohort $2,46.9 \%$ in cohort 3 , and $58.8 \%$ in cohort 4 . The portion of patients with 4 or more NSAM in the axillary specimen was: $9.0 \%$ in cohort one, $12.9 \%$ in cohort two, $16.8 \%$ in cohort three, and $28.6 \%$ in cohort four (Fig. 4).

\section{Discussion}

Since the publication of the ACOSOG Z0011 trial, an increasing number of patients have been treated accordingly $[3,17,22,24]$. Here we compared cALND rates in patients who did versus did not fulfill all eligibility criteria of the ACOSOG Z0011 trial. We found decreasing rates of cALND over time in patients with T3-4 cN0 EBC with 1-2 tumor-involved SLN undergoing BCT or mastectomy. There are already reports from clinical routine cohorts that cALND is omitted also in SLN-positive patients outside the ACOSOG Z0011 criteria, as already shown for the same cohort in patients with mastectomy [21] or for a Dutch cohort with higher tumor stage [22]. Kenny et al. have suggested that the ACOSOG Z0011 trial significantly altered axillary management in all EBC patients with positive SLN, not only in those receiving BCT [25]. Interestingly, Yao et al. reported from the US National Cancer Data Base that even in the pre-Z0011 era (1998-2011), around 22\% of mastectomy patients who were otherwise ACOSOG Z0011 eligible did not undergo cALND [26].

It must be emphasized that until now no randomized trial has been published to support a less extensive axillary surgery approach in T3-T4 cN0 SLN-positive EBC cases or in patients undergoing mastectomy. The prospective, randomized trials, AMAROS and OTOASOR, analyzed the omission of cALND in comparison to axillary radiotherapy in patients with EBC and clinically node-negative lymph nodes with positive SLN. Both trials included 
Table 1 Characteristics of the entire study cohort and the cohorts 1-4 (absolute and relative frequencies)

\begin{tabular}{|c|c|c|c|c|c|}
\hline Characteristics & Entire study cohort & $\begin{array}{l}\text { Cohort } 1 \\
\text { T1-T2 N0, 1-2 posi- } \\
\text { tive SLN and BCT }\end{array}$ & $\begin{array}{l}\text { Cohort } 2 \\
\text { T1-T2 N0, 1-2 positive } \\
\text { SLN and mastectomy }\end{array}$ & $\begin{array}{l}\text { Cohort } 3 \\
\text { T3-T4 N0, 1-2 posi- } \\
\text { tive SLN and BCT }\end{array}$ & $\begin{array}{l}\text { Cohort } 4 \\
\text { T3-T4 N0, 1-2 } \\
\text { positive SLN and } \\
\text { mastectomy }\end{array}$ \\
\hline$n$ & 188,909 & 13,741 & 4093 & 269 & 906 \\
\hline \multicolumn{6}{|l|}{ Age } \\
\hline Median (range) & $62(18-100)$ & $60(23-95)$ & $68(21-95)$ & $64(27-89)$ & 70 (20-97) \\
\hline Missing & 0 & 0 & 0 & 0 & 0 \\
\hline \multicolumn{6}{|l|}{ Age group, $n(\%)$} \\
\hline$\leq 50$ year & $41,127(21.8)$ & $3307(24.1)$ & $846(20.7)$ & $50(18.6)$ & $144(15.9)$ \\
\hline$>50$ year & $147,782(78.2)$ & $10,434(75.9)$ & $3247(79.3)$ & $219(81.4)$ & $762(84.1)$ \\
\hline \multicolumn{6}{|l|}{ ECOG status, $n(\%)$} \\
\hline 0 & $141,063(83.8)$ & $11,093(89.4)$ & $2735(77.1)$ & $197(82.8)$ & $565(71.7)$ \\
\hline 1 & $22,275(13.2)$ & $1219(9.8)$ & $646(18.2)$ & $35(14.7)$ & $171(21.7)$ \\
\hline 2 & $4261(2.5)$ & $96(0.8)$ & $168(4.7)$ & $6(2.5)$ & $52(6.6)$ \\
\hline$\geq 3$ & $697(0.4)$ & - & - & - & - \\
\hline Missing & 20,633 & 1333 & 544 & 31 & 118 \\
\hline \multicolumn{6}{|l|}{ T stage, $n(\% *)$} \\
\hline T0 & 3548 (1.9) & - & - & - & - \\
\hline Tis & $21,656(11.5)$ & - & - & - & - \\
\hline $\mathrm{T} 1$ & $93,389(49.5)$ & 7998 (58.2) & $1242(30.4)$ & - & - \\
\hline $\mathrm{T} 2$ & $56,463(29.9)$ & $5740(41.8)$ & $2849(69.6)$ & - & - \\
\hline $\mathrm{T} 3$ & $8144(4.3)$ & - & - & $175(65.1)$ & $627(69.2)$ \\
\hline $\mathrm{T} 4$ & $5463(2.9)$ & - & - & $94(34.9)$ & $279(30.8)$ \\
\hline Missing & 246 & 0 & 2 & 0 & 0 \\
\hline \multicolumn{6}{|l|}{ ER status, $n(\% *)$} \\
\hline Positive & $156,248(83.4)$ & $12,455(90.7)$ & $3710(90.7)$ & $246(91.5)$ & $811(89.6)$ \\
\hline Negative & $31,072(16.6)$ & $1277(9.3)$ & $382(9.3)$ & $23(8.6)$ & $94(10.4)$ \\
\hline Missing & 1589 & 9 & 1 & 0 & 1 \\
\hline \multicolumn{6}{|l|}{ PR status, $n(\% *)$} \\
\hline Positive & 135,903 (72.6) & $11,177(81.4)$ & $3226(78.9)$ & $221(82.16)$ & $692(76.46)$ \\
\hline Negative & $51,372(27.4)$ & 2555 (18.6) & $864(21.1)$ & $48(17.84)$ & $213(23.54)$ \\
\hline Missing & 1634 & 9 & 3 & 0 & 1 \\
\hline \multicolumn{6}{|l|}{ HER2 status $n(\% *)$} \\
\hline Positive & $22,573(13.1)$ & $1346(9.9)$ & $516(12.8)$ & $27(10.1)$ & $99(11.1)$ \\
\hline Negative & $149,374(86.9)$ & $12,199(90.1)$ & $3516(87.2)$ & 241 (89.9) & 793 (88.9) \\
\hline Missing & 16,962 & 196 & 61 & 1 & 14 \\
\hline \multicolumn{6}{|c|}{ Lymphovascular invasion, $n(\% *)$} \\
\hline Yes & $36,769(22.2)$ & $5423(42.7)$ & $1752(46.3)$ & $137(54.4)$ & $484(57.1)$ \\
\hline No & $128,851(77.8)$ & $7277(57.3)$ & $2030(53.7)$ & $115(45.6)$ & $363(42.9)$ \\
\hline Missing & 23,289 & 1041 & 311 & 17 & 59 \\
\hline \multicolumn{6}{|l|}{ Grading, $n(\% *)$} \\
\hline G1 (low) & $27,019(14.6)$ & $1841(13.4)$ & $329(8.1)$ & $15(5.6)$ & $57(6.3)$ \\
\hline G2 (intermediate) & $104,665(56.7)$ & $8793(64.1)$ & $2709(66.3)$ & $186(69.1)$ & $616(68.0)$ \\
\hline G3 (high) & $52,853(28.6)$ & $3089(22.5)$ & $1051(25.7)$ & $68(25.3)$ & $233(25.7)$ \\
\hline
\end{tabular}

$T$ tumor stage, ECOG Eastern Cooperative Oncology Group, ER estrogen, $P R$ progesterone

*The missing values were not included in the calculation of the relative frequencies

patients with mastectomy to a small extent: $17 \%(248 / 1425$ in the intervention arm) in AMAROS and $16 \%(47 / 474$ in the intervention arm) in OTOASOR. Nonetheless, these sample sizes were underpowered for a subgroup analysis [12, 13]. Another important aspect is the effect of radiotherapy on oncological outcome. The results of the 


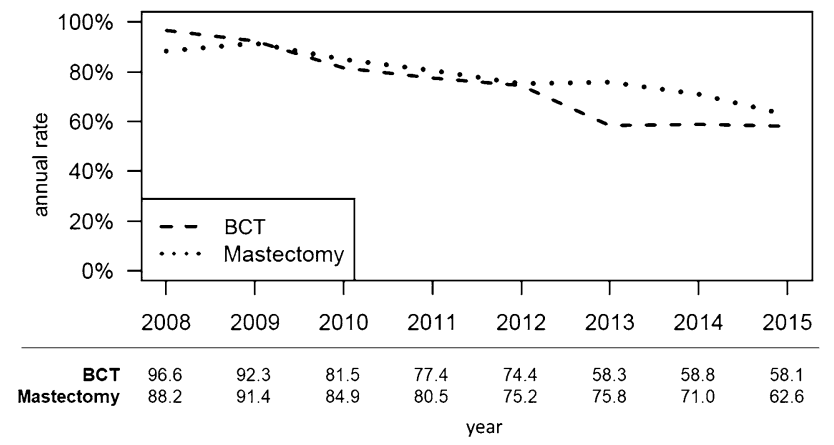

Fig. 2 Completing axillary lymph node dissection rate in patients with T3-T4 N0 early breast cancer and one or two tumor-affected sentinel lymph nodes separated for breast-conserving therapy or mastectomy between 2008 and 2015 (BCT: breast-conserving therapy)

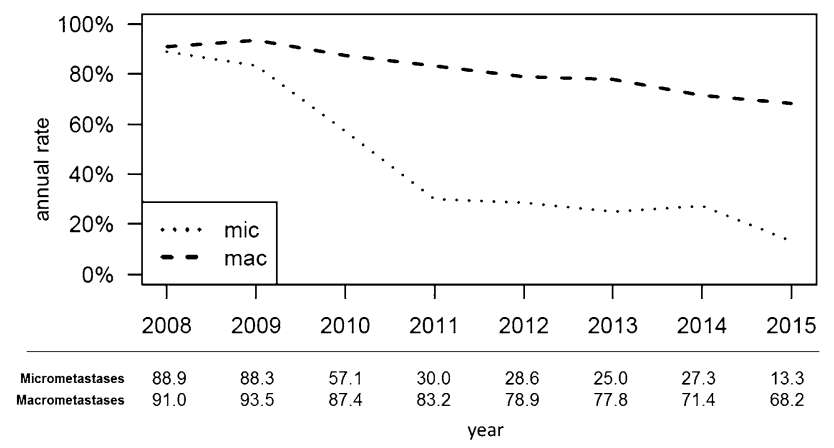

Fig. 3 Rate of completing axillary lymph node dissection in patients with T3-T4 N0 early breast cancer and one or two tumor-affected sentinel lymph nodes, separated for sentinel micrometastases (mic) or macrometastases (mac), between 2008 and 2015

ACOSOG Z0011 [6] and IBCSG 23-01 [10] trials cannot be extrapolated to SLN-positive patients treated with mastectomy, as these patients do not routinely receive adjuvant radiation therapy according to recent guidelines, e.g. the German S3 guideline [27]. Nonetheless, studies suggest that radiotherapy can be as effective as ALND in patients with mastectomy and nodal-positive disease for overall and recurrence-free survival rates [28].

Currently, randomized trials are being prepared to deliver high evidence for node-positive patients undergoing mastectomy. For example, the randomized controlled BOOG 2013-07 trial aims to investigate whether cALND can be safely omitted in SLN-positive EBC patients treated with mastectomy [29]. Further, the POSNOC trial, with a planned sample size of 1900 and a stratification for mastectomy, will assess whether SLND-alone is non-inferior to axillary radiation for women with $\leq 2$ macrometastases [30]. The SENOMAC trial includes patients with T1-T3 tumors and patients undergoing either BCT or mastectomy, and it is investigating whether SLND-alone is sufficient as axillary staging [31].
Table 2 Multivariable analysis of factors influencing the decision to perform completing axillary lymph node dissection in patients with T3-T4 cN0 early breast cancer and one or two tumor-affected sentinel lymph nodes since publication of the ACOSOG Z0011 results

Variable Odds ratio (95\% CI) $\quad p$ value

Type of hospital

General, non-academic hospital

Reference

Academic teaching hospital

1.12 (0.75-1.67)

0.576

University hospital

$1.12(0.50-2.67)$

0.783

Annual hospital caseload

$<150$

150-249

Reference

$\geq 250$

Age (years)

1.53 (0.97-2.43)

$2.16(1.30-3.62)$

Tumor stage

3

$0.96(0.94-0.98)$

4

Reference

$0.99(0.63-1.56)$

Type of metastasis

Macro

Micro

Reference

$0.08(0.04-0.17) \quad<0.001$

Sentinel removed

$0.70(0.62-0.80)$

Sentinel affected

$2.08(1.31-3.37)$

0.002

Surgical procedure

BCT Reference

BCT with re-excision

$0.92(0.39-2.25)$

0.84

Mastectomy

$1.58(0.94-2.64)$

0.08

Mastectomy with re-excision

$1.78(0.25-36.9)$

0.62

Grading

G1 (low)

G2 (intermediate)

G3 (high)

Reference

$1.05(0.47-2.22)$

0.90

Lymphovascular invasion

No

$1.21(0.50-2.84)$

Reference

$1.28(0.86-1.91)$

Histological subtype

Ductal

Reference

Lobular

$0.61(0.71-1.79)$

0.61

Other

$0.33(0.59-5.94)$

0.33

Hormone receptor status

Negative

Reference

Positive

$0.89(0.37-1.98)$

0.78

HER2 receptor status

Negative Reference

Positive

$1.12(0.59-2.18)$

0.74

ECOG performance status

0
1
2

Reference

$0.58(0.36-0.93) \quad 0.02$

$1.12(0.48-2.69)$

0.81

$C I$ confidence interval, $B C T$ breast-conserving therapy, ECOG Eastern Cooperative Oncology Group 
Fig. 4 Rates for non-sentinel metastases after completing axillary lymph node dissection for cohorts $1-4$, presented as total any and separated into three subgroups $(0,1-3$ and $\geq 4$ NSAM) ( $S L N$ sentinel lymph node, $B C T$ breast-conserving therapy)

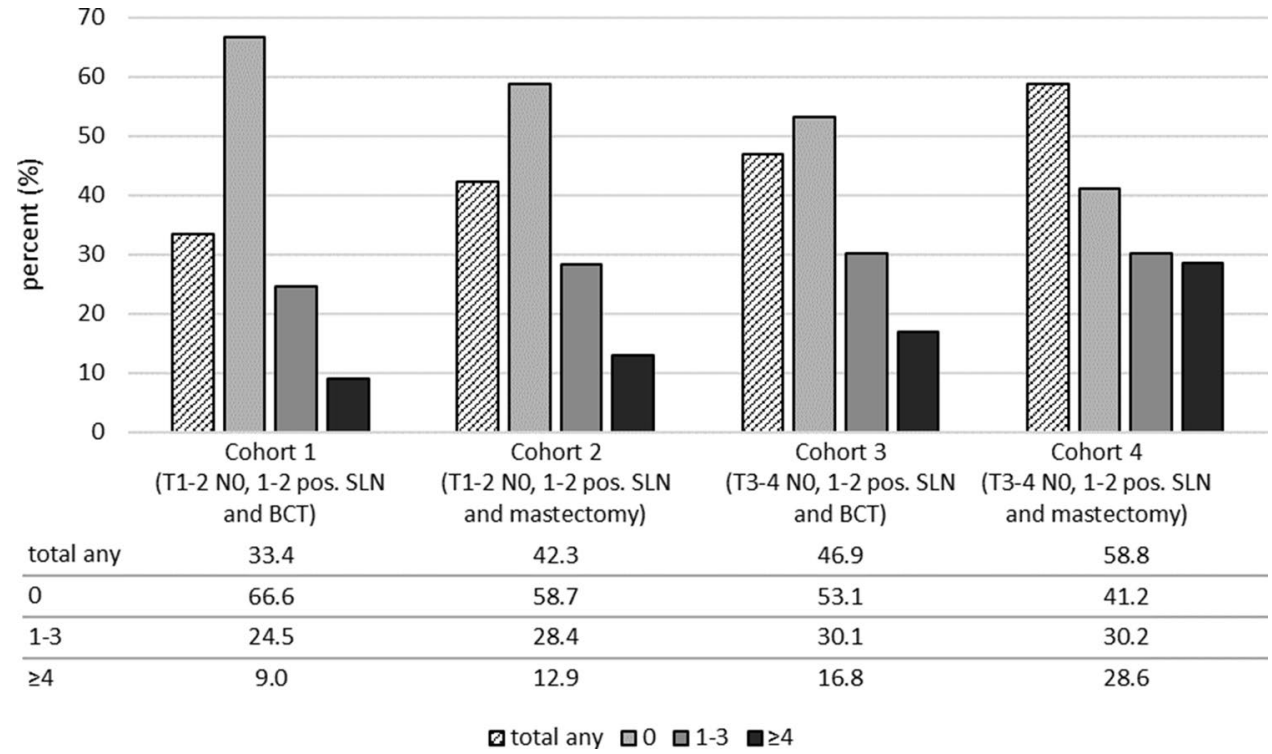

The reasons why cALND is sometimes omitted despite the lack of evidence to support omission have not been systemically examined, but it can be assumed this affects mainly vulnerable subgroups with reduced general health conditions, e.g. due to higher age. A retrospective study from the Netherlands has shown that the omission of complete axillary staging was common in selected elderly EBC patients receiving endocrine therapy with $\geq 2$ comorbidities and had no apparent impact on regional control and 10-year overall survival [32]. Similar result have been shown earlier by analyses from the US SEER database [33]. Also, in our multivariable analysis with T3-T4 EBC, higher patient age was a significant influencing factor in the omission of cALND (Tab. 2). This is comparable to earlier analyses [22]. Further important factor influencing treatment decisions to perform a cALND was the nodal tumor burden, determined by the number of involved SLNs and the number of removed SLNs. In routine clinical practice, physicians rather omitted cALND in patients with fewer tumor-affected SLNs and more removed SLNs, suggesting a higher likelihood of no further non-sentinel metastasis. Moreover, institutional factors like treatment in centers with a high annual case volume lead to higher probability of cALND which might be explained by standardized treatment procedures in high volume settings.

Results from trials were extrapolated when implementing them in clinical routine. This is based on clinically analogous assumptions in the routine decision-making process. Since larger tumors have a higher likelihood of axillary lymph node involvement, the early studies on the implementation of the SLND technique 20 years ago mostly restricted their inclusion criteria to EBC patients with tumor size $\leq 5 \mathrm{~cm}[34,35]$. Thus, in clinical routine the use of SLND was also extrapolated for larger tumors and multicentric disease. A comparable phenomenon can also be observed after the results from the ACOSOG Z0011 trials were published. Nonetheless, application of the conclusions from trial results to other populations of patients beyond the inclusion criteria must be considered with caution due to the lack of evidence and the possibility of deteriorating the oncological outcome.

In the cALND arm of the ACOSOG Z0011 trial, 27.3\% of the patients had additional involved NSAM and $13.7 \%$ even had $\geq 4$ NSAM [10]. Higher rates of NSAM in the control groups with cALND have been reported in the other randomized trials that compared the omission of CALND with radiotherapeutic interventions. In the AMAROS trial, the portion of patients with NSAM was $32.7 \%$, and the portion of patients with $\geq 4$ NSAM was $8.3 \%$ [12]. In the OTOSAR trial, the portion of patients with NSAM was 38.5\% [13]. In our study, the portion of patients with NSAM was $33.4 \%$ after cALND in the ACOSOG-eligible cohort, which is slightly higher than in the ACOSOG Z0011 trial. In contrast, the portion of patients with $\geq 4$ NSAM was lower in our study (9.0\%) than in the ACOSOG Z0011 trial [14]. Some studies have found that clinicopathological factors (such as lobular type or multifocality), type of SN metastases, and the number SN with macrometastases might possibly be related to NSAM rates and could be used in the treatment decision process [36].

Nonetheless, there have not been any studies so far that have reported the portion of patients with NSAM in cohorts not meeting the ACOSOG eligibility criteria, although nomograms have also been established for patients with mastectomy [37]. In our cohorts not meeting the ACOSOG eligibility criteria, higher portions of patients with NSAM involvement were found in comparison to the ACOSOG-eligible cohort. These were: $41.3 \%$ in T1-T2 with mastectomy 
(cohort 2), 46.9\% for T3-T4 with BCT (cohort 3), and 58.8\% for T3-T4 with mastectomy (cohort 4). Correspondingly, the portion of patients with $\geq 4$ NSAM found in the cALND specimen range from 12.9 to $28.6 \%$, which suggests a high residual tumor burden if cALND is omitted (Fig. 4).

Axillary lymph node status still has an important influence on adjuvant treatment decisions, especially for patients with favorable tumor biology, as previous discussed for this cohort [14]. Retrospective cohorts from the Netherlands have illustrated this impact on the decision for adjuvant chemotherapy if cALND was omitted: T1-T2 N0 SLN-positive EBC patients treated with cALND had a higher probability of receiving adjuvant chemotherapy compared with SLND-only patients [38]. The authors emphasized that treatment decisions were not only based on guidelines and tumor characteristics but also on the preferences of physicians and patients. Further studies will have to identify factors that prognosticate good outcomes even without cALND, as was done for example for patients with microscopic extracapsular extension [39].

The use neoadjuvant chemotherapy, which was excluded from ACOSOG Z011, contributes to the goal of minimizing the use of ALND and its associated morbidity. Patients with larger tumors and an aggressive subtype, i.e. HER2-enriched and TN will receive neoadjuvant chemotherapy (NAC). In these patients SLNB after NAC in clinically node-negative patients has the potential to downstage microscopic nodal disease and thus avoid ALND [40].

This study is limited by its post hoc nature and lack of outcome data. Furthermore, incomplete information about the cT stage led to the use of the pT stage to determine whether patients met the ACOSOG Z0011 inclusion criteria. We considered this approach reasonable though, because the pT stage and cT stage were concordant for most cases in our cohort.

\section{Conclusion}

To reduce the morbidity in the management of breast cancer patients, surgeons should aim to minimize the rates of cALND among clinically node-negative patients with pathologically node-positive disease. Rates for cALND have decreased substantially in routine care. A rising prevalence of additional NSAM tumor burden is linked with the extension of the ACOSOG Z0011 study eligibility criteria. The goal is to identify further patient populations in which a reduced axillary surgery is possible without compromising oncological outcome. So far, there is no evidence that the substantial tumor burden left behind has no disadvantage on outcome in cases with extended ACOSOG Z0011 eligibility criteria, especially T3-T4 tumors. However, selected subgroups might still benefit in saving them from unnecessary morbidity from cALND in an individual risk-benefit analysis.

Acknowledgements The authors would like to thank all clinical research associates from the participating breast units for documentation and data management, and we would like to thank the WBC for providing the data. The authors would also like to thank Michael Hanna, PhD, (Mercury Medical Research \& Writing) for proof-reading the manuscript.

Funding This research received funding from the German Cancer Aid (Grant No. 70112082). The funding source had no role in the study design; the collection, analysis, or interpretation of the data; the writing of the report; or the decision to submit the article for publication. Open Access funding provided by Projekt DEAL.

Data availability The datasets are available from the corresponding author on reasonable request.

\section{Compliance with ethical standards}

Conflict of interest Fabian Riedel declares he has no conflict of interests. Joerg Heil declares he has no conflict of interest. Mareike Moderow declares she has no conflict of interest. Manuel Feisst declares he has no conflict of interest. Alexandra von Au declares she has no conflict of interest. Christoph Domschke declares he has no conflict of interest. Laura Michel declares she has no conflict of interest. Benedikt Schaefgen declares he has no conflict of interest. Michael Golatta declares he has no conflict of interest. André Hennigs declares he has no conflict of interest.

Ethical approval All procedures performed in studies involving human participants were in accordance with the ethical standards of the institutional and/or national research committee and with the 1964 Helsinki declaration and its later amendments or comparable ethical standards. The study was approved by the ethics committee of the University of Heidelberg.

Informed consent The study was deemed to be without risk, including only analysis of anonymized, routinely collected data; consequently, the ethics committee of the University of Heidelberg did not request approval for patient consent for this designated analysis. Informed consent was obtained from all individual participants for the data acquisition of the benchmarking process.

Open Access This article is licensed under a Creative Commons Attribution 4.0 International License, which permits use, sharing, adaptation, distribution and reproduction in any medium or format, as long as you give appropriate credit to the original author(s) and the source, provide a link to the Creative Commons licence, and indicate if changes were made. The images or other third party material in this article are included in the article's Creative Commons licence, unless indicated otherwise in a credit line to the material. If material is not included in the article's Creative Commons licence and your intended use is not permitted by statutory regulation or exceeds the permitted use, you will need to obtain permission directly from the copyright holder. To view a copy of this licence, visit http://creativecommons.org/licenses/by/4.0/. 


\section{References}

1. Whelan TJ, Olivotto IA, Parulekar WR, Ackerman I, Chua BH, Nabid A et al (2015) Regional nodal irradiation in early-stage breast cancer. N Engl J Med 373(4):307-316

2. Moebus V, Jackisch C, Lueck HJ, du Bois A, Thomssen C, Kurbacher $C$ et al (2010) Intense dose-dense sequential chemotherapy with epirubicin, paclitaxel, and cyclophosphamide compared with conventionally scheduled chemotherapy in high-risk primary breast cancer: mature results of an AGO phase III study. J Clin Oncol 28(17):2874-2880

3. Riedel F, Heil J, Golatta M, Schaefgen B, Hug S, Schott S et al (2019) Changes of breast and axillary surgery patterns in patients with primary breast cancer during the past decade. Arch Gynecol Obstet 299(4):1043-1053

4. Schwartz GF, Giuliano AE, Veronesi U (2002) Proceedings of the consensus conference on the role of sentinel lymph node biopsy in carcinoma of the breast, April 19-22, 2001, Philadelphia Pennsylvania. Cancer 94(10):2542-2551

5. Giuliano AE, McCall L, Beitsch P, Whitworth PW, Blumencranz $P$, Leitch AM et al (2010) Locoregional recurrence after sentinel lymph node dissection with or without axillary dissection in patients with sentinel lymph node metastases: the American College of Surgeons Oncology Group Z0011 randomized trial. Ann Surg 252(3):426-433

6. Giuliano AE, Ballman KV, McCall L, Beitsch PD, Brennan MB, Kelemen PR et al (2017) Effect of axillary dissection vs no axillary dissection on 10-year overall survival among women with invasive breast cancer and sentinel node metastasis: the ACOSOG Z0011 (Alliance) randomized clinical trial. JAMA 318(10):918-926

7. Maguire A, Brogi E (2016) Sentinel lymph nodes for breast carcinoma: a paradigm shift. Arch Pathol Lab Med 140(8):791-798

8. Guth U, Myrick ME, Viehl CT, Schmid SM, Obermann EC, Weber WP (2012) The post ACOSOG Z0011 era: does our new understanding of breast cancer really change clinical practice? Eur J Surg Oncol 38(8):645-650

9. Morrow M, Giuliano AE (2011) To cut is to cure: can we really apply Z11 in practice? Ann Surg Oncol 18(9):2413-2415

10. Galimberti V, Cole BF, Zurrida S, Viale G, Luini A, Veronesi P et al (2013) Axillary dissection versus no axillary dissection in patients with sentinel-node micrometastases (IBCSG 23-01): a phase 3 randomised controlled trial. Lancet Oncol 14(4):297-305

11. Galimberti V, Cole BF, Viale G, Veronesi P, Vicini E, Intra M et al (2018) Axillary dissection versus no axillary dissection in patients with breast cancer and sentinel-node micrometastases (IBCSG 23-01): 10-year follow-up of a randomised, controlled phase 3 trial. Lancet Oncol 19(10):1385-1393

12. Donker M, van Tienhoven G, Straver ME, Meijnen P, van de Velde CJ, Mansel RE et al (2014) Radiotherapy or surgery of the axilla after a positive sentinel node in breast cancer (EORTC 1098122023 AMAROS): a randomised, multicentre, open-label, phase 3 non-inferiority trial. Lancet Oncol 15(12):1303-1310

13. Savolt A, Peley G, Polgar C, Udvarhelyi N, Rubovszky G, Kovacs E et al (2017) Eight-year follow up result of the OTOASOR trial: the optimal treatment of the axilla-surgery or radiotherapy after positive sentinel lymph node biopsy in early-stage breast cancer: a randomized, single centre, phase III, non-inferiority trial. Eur J Surg Oncol 43(4):672-679

14. Riedel F, Heil J, Feisst M, Rezai M, Moderow M, Sohn C et al (2019) Non-sentinel axillary tumor burden applying the ACOSOG Z0011 eligibility criteria to a large routine cohort. Breast Cancer Res Treat 177(2):457-467

15. Ditsch N, Untch M, Thill M, Muller V, Janni W, Albert US et al (2019) AGO recommendations for the diagnosis and treatment of patients with early breast cancer: update 2019. Breast Care (Basel) 14(4):224-245

16. Hennigs A, Köpke M, Feißt M, Riedel F, Rezai M, Nitz U et al (2019) Which patients with sentinel node-positive breast cancer after breast conservation still receive completion axillary lymph node dissection in routine clinical practice? Breast Cancer Res Treat 173(2):429-438

17. Morrow M, Jagsi R, McLeod MC, Shumway D, Katz SJ (2018) Surgeon attitudes toward the omission of axillary dissection in early breast cancer. JAMA Oncol 4(11):1511-1516

18. Bhatt NR, Boland MR, McGovern R, Lal A, Tormey S, Lowery AJ et al (2018) Upper limb lymphedema in breast cancer patients in the era of Z0011, sentinel lymph node biopsy and breast conservation. Ir J Med Sci 187(2):327-331

19. Fillion MM, Glass KE, Hayek J, Wehr A, Phillips G, Terando A et al (2017) healthcare costs reduced after incorporating the results of the American College of Surgeons Oncology Group Z0011 trial into clinical practice. Breast J 23(3):275-281

20. Cody HS (2017) Extending ACOSOG Z0011 to encompass mastectomy: what happens without RT? Ann Surg Oncol 24(3):621-623

21. Hennigs A, Riedel F, Feisst M, Kopke M, Rezai M, Nitz U et al (2019) Evolution of the use of completion axillary lymph node dissection in patients with T1/2N0M0 breast cancer and tumourinvolved sentinel lymph nodes undergoing mastectomy: a Cohort study. Ann Surg Oncol 26(8):2435-2443

22. Poodt IGM, Spronk PER, Vugts G, van Dalen T, Peeters M, Rots ML et al (2018) Trends on axillary surgery in nondistant metastatic breast cancer patients treated between 2011 and 2015: a dutch population-based study in the ACOSOG-Z0011 and AMAROS Era. Ann Surg 268(6):1084-1090

23. Brucker SY, Schumacher C, Sohn C, Rezai M, Bamberg M, Wallwiener D (2008) Onkologische Qualitätssicherung am Beispiel des Mammakarzinom-Benchmarkings interdisziplinärer Brustzentren. Senologie-Zeitschrift für Mammadiagnostik und -therapie 5(03):143-155

24. Yi M, Kuerer HM, Mittendorf EA, Hwang RF, Caudle AS, Bedrosian I et al (2013) Impact of the american college of surgeons oncology group Z0011 criteria applied to a contemporary patient population. J Am Coll Surg 216(1):105-113

25. Kenny TC, Dove J, Shabahang M, Woll N, Hunsinger M, Morgan A et al (2016) Widespread implications of ACOSOG Z0011: effect on total mastectomy patients. Am Surg 82(1):53-58

26. Yao K, Liederbach E, Pesce C, Wang CH, Winchester DJ (2015) Impact of the American College of Surgeons Oncology Group Z0011 randomized trial on the number of axillary nodes removed for patients with early-stage breast cancer. J Am Coll Surg 221(1):71-81

27. Wockel A, Festl J, Stuber T, Brust K, Krockenberger M, Heuschmann PU et al (2018) Interdisciplinary screening, diagnosis, therapy and follow-up of breast cancer. guideline of the DGGG and the DKG (S3-Level, AWMF registry number 032/045OL, December 2017): part 2 WITH recommendations for the therapy of primary, recurrent and advanced breast cancer. Geburtshilfe Frauenheilkd. 78(11):1056-1088

28. Fu Y, Chung D, Cao MA, Apple S, Chang H (2014) Is axillary lymph node dissection necessary after sentinel lymph node biopsy in patients with mastectomy and pathological N1 breast cancer? Ann Surg Oncol 21(13):4109-4123

29. van Roozendaal LM, de Wilt JH, van Dalen T, van der Hage JA, Strobbe LJ, Boersma LJ et al (2015) The value of completion axillary treatment in sentinel node positive breast cancer patients undergoing a mastectomy: a Dutch randomized controlled multicentre trial (BOOG 2013-07). BMC Cancer 15:610 
30. Goyal A, Dodwell D (2015) POSNOC: a randomised trial looking at axillary treatment in women with one or two sentinel nodes with macrometastases. Clin Oncol (R Coll Radiol) 27(12):692-695

31. de Boniface J, Frisell J, Andersson Y, Bergkvist L, Ahlgren J, Ryden L et al (2017) Survival and axillary recurrence following sentinel node-positive breast cancer without completion axillary lymph node dissection: the randomized controlled SENOMAC trial. BMC Cancer 17(1):379

32. Poodt IGM, Schipper RJ, Vugts G, Woensdregt K, van der Sangen M, Voogd AC et al (2018) The rationale for and long-term outcome of incomplete axillary staging in elderly women with primary breast cancer. Eur J Surg Oncol 44(11):1714-1719

33. Caretta-Weyer H, Greenberg CG, Wilke LG, Weiss J, LoConte NK, Decker M et al (2013) Impact of the American College of Surgeons Oncology Group (ACOSOG) Z0011 trial on clinical management of the axilla in older breast cancer patients: a SEERmedicare analysis. Ann Surg Oncol 20(13):4145-4152

34. Veronesi U, Paganelli G, Viale G, Luini A, Zurrida S, Galimberti $\mathrm{V}$ et al (2003) A randomized comparison of sentinel-node biopsy with routine axillary dissection in breast cancer. $\mathrm{N}$ Engl $\mathrm{J}$ Med 349(6):546-553

35. Krag DN, Anderson SJ, Julian TB, Brown AM, Harlow SP, Costantino JP et al (2010) Sentinel-lymph-node resection compared with conventional axillary-lymph-node dissection in clinically node-negative patients with breast cancer: overall survival findings from the NSABP B-32 randomised phase 3 trial. Lancet Oncol 11(10):927-933
36. Majid S, Ryden L, Manjer J (2019) Determinants for non-sentinel node metastases in primary invasive breast cancer: a populationbased cohort study of 602 consecutive patients with sentinel node metastases. BMC Cancer 19(1):626

37. Wang XY, Wang JT, Guo T, Kong XY, Chen L, Zhai J et al (2019) Risk factors and a predictive nomogram for non-sentinel lymph node metastases in Chinese breast cancer patients with one or two sentinel lymph node macrometastases and mastectomy. Curr Oncol 26(2):e210-e215

38. Poodt IGM, Rots ML, Vugts G, van Dalen T, Kuijer A, Vriens B et al (2018) The administration of adjuvant chemo(-immuno) therapy in the post ACOSOG-Z0011 era; a population based study. Eur J Surg Oncol 44(8):1151-1156

39. Barrio AV, Downs-Canner S, Edelweiss M, Van Zee KJ, Cody HS 3rd, Gemignani ML et al (2019) Microscopic extracapsular extension in sentinel lymph nodes does not mandate axillary dissection in Z0011-eligible patients. Ann Surg Oncol. (epub ahead of print)

40. Pilewskie M, Morrow M (2017) Axillary nodal management following neoadjuvant chemotherapy: a review. JAMA Oncol 3(4):549-555

Publisher's Note Springer Nature remains neutral with regard to jurisdictional claims in published maps and institutional affiliations. 